\title{
Role of sensory and motor intensity of electrical stimulation on fibroblastic growth factor-2 expression, inflammation, vascularization, and mechanical strength of full-thickness wounds
}

\author{
Mohammad Reza Asadi, MSc; ${ }^{1}$ Giti Torkaman, PhD; ${ }^{*}$ Mehdi Hedayati, PhD; ${ }^{2}$ Mahmood Mofid, MSc $^{3}$ \\ ${ }^{1}$ Physical Therapy Department, Faculty of Medical Sciences, Tarbiat Modares University, Tehran, Islamic Republic of \\ Iran; ${ }^{2}$ Cellular and Molecular Research Center, Research Institute for Endocrine Sciences, Shahid Beheshti University of \\ Medical Sciences, Tehran, Islamic Republic of Iran; ${ }^{3}$ Anatomy Department, Faculty of Medical Sciences, Baqiyatallah \\ University of Medical Sciences, Tehran, Islamic Republic of Iran
}

\begin{abstract}
Electrical stimulation (ES) profoundly affects angiogenesis by modulating the production of angiogenic factors. We evaluated the effect of sensory (direct current, 600 microamperes) and motor (monophasic pulse current, 2.5 to 3 milliamperes, 300-microsecond pulse duration, $100 \mathrm{~Hz}$ ) intensities of cathodal current on the release of fibroblastic growth factor-2 (FGF-2) at the wound site and also the biomechanical and histological properties of healed skin. Ninety-six male, SpragueDawley rats were randomly assigned into one control and two experimental groups. A full-thickness skin incision was made on the dorsal region of each animal. The experimental groups received 10 sessions of ES (sensory or motor) for 1 hour per day every other day. The results showed that FGF-2 levels in the sensory group were significantly greater than in the other groups on the third day. In the motor group, FGF-2 levels were significantly decreased compared with the control group. There were no significant differences between the normalized ultimate strength and stiffness in the groups, but they tended to be higher in the motor ES group. We conclude that the application of sensory ES during the early stage of wound healing may have a beneficial effect on wound healing by inducing the release of angiogenic factors and decreasing the duration of the inflammation phase.
\end{abstract}

Key words: angiogenesis, cathodal stimulation, electrical stimulation, FGF-2, fibroblastic growth factor-2, full-thickness wound, mast cell, mechanical strength, rat, wound healing.

\section{INTRODUCTION}

Wound healing is a complex biological process that requires interactions between a variety of cells, and growth factors have a key role in regulating these interactions [12]. Several growth factors have been implicated as direct mediators of angiogenesis, the formation of new blood vessels from pre-existing blood vessels during wound healing, including basic fibroblastic growth factor (bFGF), fibroblastic growth factor-2 (FGF-2), platelet-derived growth factor, and vascular endothelial growth factor (VEGF). These angiogenic factors are released predominantly at the wound site by numerous cell types, including macrophages, neutrophils, fibroblasts, lymphocytes, and endothelial cells [3-8].

\footnotetext{
Abbreviations: $\mathrm{bFGF}=$ basic fibroblastic growth factor, $\mathrm{DC}=$ direct current, ELISA = enzyme-linked immunosorbent assay, $\mathrm{ES}=$ electrical stimulation, FGF-2 = fibroblastic growth factor-2, $\mathrm{H} \& \mathrm{E}=$ hematoxylin and eosin, $\mathrm{PNL}=$ polymorphonuclear leukocyte, $\mathrm{VEGF}=$ vascular endothelial growth factor.

*Address all correspondence to Giti Torkaman, PhD; Physical Therapy Department, Tarbiat Modares University, Tehran, Islamic Republic of Iran; +98-21-82884509; fax: +98-21-88006544. Email: torkamg@modares.ac.ir http://dx.doi.org/10.1682/JRRD.2012.04.0074
} 
Electrical stimulation (ES) has long been used for wound healing [9-15], and recently, it has been shown to possibly be clinically applicable for angiogenesis by stimulating the formation of angiogenic factors [16-21]. There are some reports that ES induces an increase in the release of VEGF in muscle, both when ES causes muscle contraction and following subthreshold stimulation that does not induce contraction [18-23]. To investigate the effect of ES on the release of FGF-2 in muscle, Shen and colleagues applied different frequencies of ES to ischemic skeletal muscles of rabbits for 4 weeks [24]. Their results showed that FGF-2 expression did not change in any groups. Nagasaka et al. reported that bFGF expression was not increased in rat skeletal muscles when low-voltage ES was applied with a stimulus intensity below the threshold for muscle contraction over a period of 5 days [18]. Düsterhöft and colleagues studied FGF and FGF receptor expression in lowfrequency stimulated rat muscles and rat satellite cell cultures [25]. They found that FGF-2 expression is enhanced in stimulated muscles. Furthermore, there is evidence that ES increases the release of angiogenic factors at the wound site. Morris and colleagues applied ES (square wave-pulsed direct current [DC]) with both a $110 \mu$ s pulse duration and a $5 \mu$ s pulse duration to ischemic wounds in the ears of rabbits for 7, 14, or 21 days [21]. Both groups received ES at an amplitude of $11 \mathrm{~mA}$, with an interpulse interval of $40 \mathrm{~ms}$. They found that ES with a $110 \mu$ s pulse duration induces a significant increase in VEGF levels on the fourth day following injury. Fredericks et al. examined mRNA levels of FGF-2 in response to DC ES in a rabbit posteriorlateral fusion model [26]. They found that FGF-2 mRNA expression was significantly increased in the experimental group. Sato et al. demonstrated that ES induced production of FGF-2 in cultured retinal Müller cells [27]. Zhao et al. reported that direct effects of electric fields on endothelial cells induce the release of VEGF in culture [17].

FGF-2 stimulates the proliferation of fibroblasts that give rise to the formation of granulation tissue and the angiogenic-related growth of blood vessels at the wound site; therefore, FGF-2 is very important in the woundhealing process [7-8,28-29]. We found no in vivo study in the literature that directly examined the effects of ES on FGF-2 expression during wound healing. In our previous study, we applied ES to an incisional wound on the back in rats for 3 and 7 days (48 rats were assigned to two experimental groups and a control group). One experimental group received $600 \mu \mathrm{A}$ of DC (sensory intensity group), and the other experimental group received $2.5 \mathrm{~mA}$ of monophasic current (motor intensity group). We measured the VEGF level in muscle and skin on the third and seventh days after surgical incision. Our results showed that skin VEGF levels were significantly higher in the sensory group than in the motor and control groups on the seventh day postinjury. However, no difference was found in muscle VEGF levels on the third and seventh days postinjury [16].

Several groups of investigators have examined histological parameters in wounds of animals treated with ES [30-33], but the effects of different intensities of ES on histological parameters and growth factor expression have not yet been investigated.

This study was designed to evaluate the effect of sensory $(600 \mu \mathrm{A})$ and motor (threshold of contraction) intensities of cathodal ES on the release of FGF-2 at the wound site, separately in skin and muscle, and its relation to proliferation of inflammatory cells, collagen fiber alignment, and angiogenesis. In order to better evaluate the two different intensities on wound healing, we measured tensile strength and stiffness of healed skin on day 21 postinjury.

In wound healing, FGF-2 is released mainly by macrophages, neutrophils, fibroblasts, and endothelial cells [7,28-29], and it has been reported that these cells migrate toward the cathode (negative polarity) in an electrical field $[9,34]$. Thus, it appears that applying cathodal ES to the wound site may increase the release of FGF-2.

\section{MATERIALS AND METHODS}

\section{Animals}

Ninety-six healthy, male Sprague-Dawley rats (weighing 250-300 g; Razi Vaccine and Serum Research Institute Karaj; Tehran, Iran) were used in this study. Animals were housed one per cage and maintained according to the controlled conditions outlined in the experimental guidelines of Tarbiat Modares University with a 12-hour light/dark cycle. The study was approved by the Ethics Commission of Tarbiat Modares University, Tehran, Islamic Republic of Iran.

\section{Wounding and Treatment Protocol}

The rats were anesthetized using a mixture of xylazine hydrochloride $(20 \mathrm{mg} / \mathrm{mL})$ and ketamine hydrochloride (100 mg/mL, Alfasan; Woerden, the Netherlands) (xylazine:ketamine ratio of $1: 9 \mathrm{~mL}$ and dose of $1 \mathrm{~mL} / \mathrm{kg}$ ). The 
hairs on the middle of the back of each rat were shaved, and the area was cleaned with betadine antiseptic solution (Purdue Products LP; Stanford, Connecticut). Following sterilization, a $2.5 \mathrm{~cm}$, longitudinal, full-thickness incision was made at a distance of $1 \mathrm{~cm}$ from the midline (spinal column) on the right side. The wounds were made through the skin and panniculus carnosus and were left unsutured.

The rats were randomly assigned into three groups (one control and two experimental groups), with each group consisting of 32 rats. Each group was divided into three subgroups according to the study period: day 3 ( 8 rats were studied to determine tissue FGF-2 levels and 2 rats were used for histological study), day 7 ( 8 rats were studied to determine tissue FGF-2 levels and 2 rats were used for histological study), and day 21 (2 rats were used for histological study and 10 rats for biomechanical study) postinjury. Treatment began 24 hours after wounding. Details of the method employed for ES application have been described previously [16]. The cathodal active electrode was placed on the incision wound area on top of sterile gauze moistened with normal saline solution, and an indifferent electrode was placed on the shaved area contralateral to the wound, at the highest part of back. Prior to treatment, the rats were placed in individual restraining devices to minimize movement during treatment, and the electrodes were fixed with straps to prevent electrode displacement. The polarity of the active electrode was negative during all of the treatment sessions for the experimental groups. In one of the experimental groups (sensory ES group), $600 \mu \mathrm{A}$ of DC was applied for 1 hour per day, every other day, for 3,7 , or 21 days. In the other experimental group (motor ES group), 2.5 to $3 \mathrm{~mA}$ of monophasic pulsed current (an intensity high enough to elicit a visible minimum contraction) with a pulse duration of $300 \mu \mathrm{s}$ and a frequency of $100 \mathrm{~Hz}$ was applied for 1 hour per day, every other day, for 3, 7, or 21 days. The electrical stimulation device used in this study was a BTL 5000 series device (BTL Industries, Ltd; Stevenage, United Kingdom). Electrodes in the control group were placed in locations identical to those used in the experimental groups, with the exception that no current was delivered through the electrodes.

\section{Tissue Preparation and FGF-2 Level Determination}

On days 3 and 7 postinjury, 8 rats in each group were sacrificed by chloroform inhalation and wound strips along the incision, including $3 \mathrm{~mm}$ from the edges, were removed and used as tissue samples to examine the FGF-2 protein content in the skin. Rectangular pieces $\left(0.5 \times 1 \mathrm{~cm}^{2}\right)$ of muscle tissue under the wound area were subsequently excised to determine the FGF-2 protein content in muscle.

Tissue samples were homogenized $(100 \mathrm{mg} / \mathrm{mL})$ in PBS (phosphate-buffered saline, pH 7.4, $100 \mathrm{mM}$ ). The buffer contained a cocktail of antiproteases (PMSF [phenylmethyl sulfonyl fluoride], EDTA [ethylenediaminetetraacetic acid], aprotinin). The homogenates were centrifuged at $12,000 \mathrm{rpm}$ for $15 \mathrm{~min}$ at $4{ }^{\circ} \mathrm{C}$. The supernatant was collected and stored at $-80{ }^{\circ} \mathrm{C}$ until used. FGF-2 was determined with an enzyme-linked immunosorbent assay (ELISA) kit (USCN LIFE Science Inc; Wuhan, China). Briefly, standards or samples $(50 \mu \mathrm{L})$ were pipetted into each antibody-coated well containing $50 \mu \mathrm{L}$ assay diluent and incubated for $1 \mathrm{~h}$ at $37{ }^{\circ} \mathrm{C}$, The wells were washed three times with wash solution, and then $100 \mu \mathrm{L}$ of FGF-2 conjugate was added to each well. The samples were again incubated for $30 \mathrm{~min}$ at $37^{\circ} \mathrm{C}$. After washing five times, we added $90 \mu \mathrm{L}$ substrate solution to each well. Samples were incubated for 15 to $25 \mathrm{~min}$ at $37^{\circ} \mathrm{C}$, after which, $50 \mu \mathrm{L}$ of stop solution was added to each well. Optical densities of the wells were measured using a microplate ELISA reader (Sunrise Moder, Tecan Co; Vienna, Austria) at a wavelength of $450 \mathrm{~nm}$. The FGF-2 concentration in the tissue samples was calculated from the standard curve and normalized by the weight of the skin.

\section{Tissue Preparation and Histological Study}

On days 3, 7, and 21 postinjury, two rats in each group were sacrificed by chloroform inhalation and fullthickness skin, including the margin of the wound and subcutaneous tissue, was excised and fixed in formaldehyde. These formalin-fixed tissues were subsequently processed through graded alcohol solutions and embedded in paraffin. The blocks were sectioned ( $5 \mu \mathrm{m}$ thick) and mounted on microscope slides. The presence of edema and polymorphonuclear leukocyte (PNL) infiltrate on slides stained with hematoxylin and eosin (H\&E) was classified using a semiquantitative scale: absent (0), discreet $(+,<25 \%)$, moderate $(++, 25 \%-50 \%)$, and intense $(+++,>50 \%)$.

Mast cells were counted in 20 areas in each slide stained with toluidine blue. We quantified the number of vessels by counting them in 10 areas in each slide stained with H\&E. Collagen density was qualitatively assessed on day 21 after staining with Van Gieson. 


\section{Tissue Preparation and Biomechanical Study}

On day 21 postinjury, 10 animals in each group were sacrificed by chloroform inhalation and tissue samples were collected to perform the uniaxial tensile test. The tissue samples, 5 to $7 \mathrm{~cm}$ long and $3 \mathrm{~cm}$ wide, were taken perpendicular to the initial incision direction. To avoid measurement errors caused by tissue differences among the animals of each group and to establish an intra-animal control for higher precision and normalization of data, we also took a sample of adjacent healthy skin. The tissue samples were placed in a normal saline solution $(0.9 \%)$ before testing.

The uniaxial tensile test was performed using a material testing machine (model Z 2.5, Zwick Gmbh \& Co; Ulm-Einsingen, Germany). The rate of the tensile test was $20 \mathrm{~mm} / \mathrm{min}$. After the test, the load-deformation curve was obtained. To evaluate the biomechanical behavior, we measured ultimate tensile strength (Fmax, newtons), stiffness (newtons per millimeter), and deformation at Fmax (strain percent). After data collection, we normalized the measurements related to the values of adjacent healthy skin using the following equation: Normalized parameter $=($ value of wound sample/value of healthy sample) $\times 100$.

\section{Statistical Analysis}

The statistical analysis was performed using SPSS statistical software (version 18.0, IBM; Armonk, New York). The differences between the groups for levels of FGF-2 were evaluated using the Mann-Whitney U-test. One-way analysis of variance and Tukey's test were used to compare data related to mast cells, new blood vessels, and biomechanical parameters between experimental and control groups. We considered $p<0.05$ statistically significant.

\section{RESULTS}

\section{FGF-2 Protein Levels in Skin Wound Tissue}

The levels of FGF-2 protein in skin wound tissue for the different groups are shown in Figure 1. On day 3 postinjury, skin FGF-2 protein levels in the sensory group were significantly higher than those in the motor and control groups ( $p=0.001$ and $p=0.02$, respectively) and those in the motor group were significantly lower than those in the control group $(p=0.03)$. On day 7 postinjury, skin FGF-2 protein levels in the motor group were significantly lower than those in the control group $(p=0.007)$, but differences between the sensory and control groups were not significant $(p=0.1)$.

\section{FGF-2 Protein Levels in Muscle Tissue}

The FGF-2 protein levels in muscle tissue for the different groups are shown in Figure 2. There were no significant differences in muscle FGF-2 levels between groups on days 3 and 7 ( $p=0.7$ and $p=0.11$, respectively).

\section{Histological Results}

The numbers of PNLs for the experimental and control groups on days 3, 7, and 21 are shown in Table 1. Proliferation of PNLs in the sensory group was lower

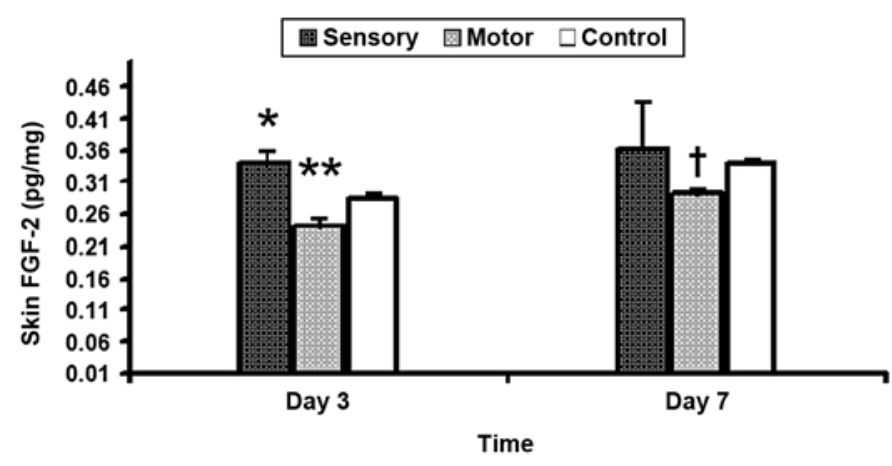

Figure 1.

Skin fibroblastic growth factor-2 (FGF-2) levels on days 3 and 7 postinjury. Values are expressed as mean \pm standard error of mean. ${ }^{*} p<0.05$ compared with control- and motor-group values; ${ }^{* *} p<0.05$ compared with control group; ${ }^{\dagger} p<0.05$ compared with control group.

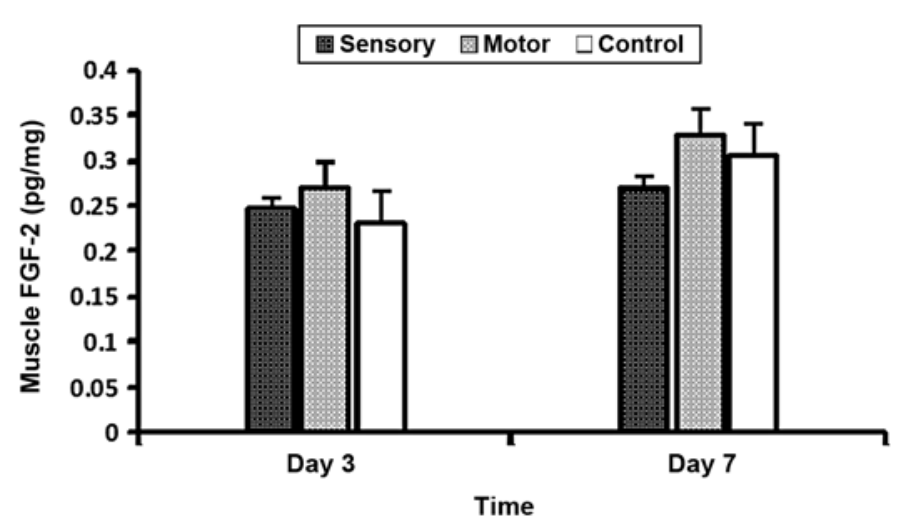

Figure 2.

Muscle fibroblastic growth factor-2 (FGF-2) levels on days 3 and 7 postinjury. Values are expressed as mean \pm standard error of mean. 
Table 1.

Polymorphonuclear leukocyte (PNL) counts (percent) within wound site in experimental and control groups on days 3,7 , and 21 postinjury.

\begin{tabular}{|c|c|c|c|c|c|c|c|}
\hline \multirow{2}{*}{ Group } & \multicolumn{2}{|c|}{ Day 3} & \multicolumn{3}{|c|}{ Day 7} & \multicolumn{2}{|c|}{ Day21 } \\
\hline & Moderate & Intense & Moderate & Discreet & Absent & Discreet & Absent \\
\hline Sensory & 90 & 10 & - & 90 & 10 & - & 100 \\
\hline Motor & 70 & 30 & - & 100 & - & 30 & 70 \\
\hline Control & 80 & 20 & 10 & 90 & - & 40 & 60 \\
\hline
\end{tabular}

than that in the motor and control groups on days 3 and 7. Furthermore, these cells were not observed at the wound site in the sensory group on day 21 postinjury.

On day 3 postinjury, the number of mast cells in the motor group was significantly higher than that in the sensory and control groups $(p<0.001$ and $p=0.001$, respectively) (Figure 3). Moreover, the number of new blood vessels in the motor group was significantly higher than that in the control group $(p=0.007)$ (Figure 4).

On day 7 postinjury, the number of mast cells was significantly decreased in the sensory and motor groups compared with the control group ( $p=0.03$ and $p=0.02$, respectively) (Figure 3). The number of new blood vessels was higher in the sensory and control groups compared with the motor group, but this difference was not significant (Figure 4).

On day 21 postinjury, the number of mast cells was completely decreased in all groups and no significant difference was found between groups (Figure 3).

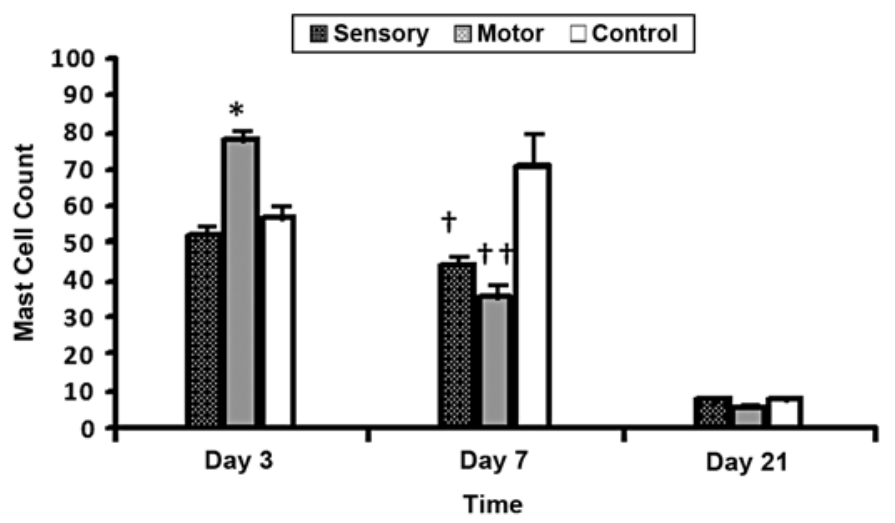

Figure 3.

Number of mast cells at wound site in experimental and control groups on days 3, 7, and 21 postinjury. Values are expressed as mean \pm standard error of mean. ${ }^{*} p<0.05$ compared with control and sensory values; ${ }^{\dagger} p<0.05$ compared with control values; ${ }^{\dagger \dagger} p<0.05$ compared with control values.

\section{Biomechanical Results}

On day 21 postinjury, the motor group had the highest percent of normalized stiffness and strength compared with the sensory and control groups. However, there was no significant difference between groups (Table 2).

\section{DISCUSSION}

ES has beneficial effects on the wound-healing process [9-15,35-37], but the mechanism of these effects remains unclear. Angiogenesis factors play an important role in various phases of wound healing [2-8]. In a fullthickness wound, elevated levels of FGF-2 are found immediately in wound fluid, but significant expression of FGF-2 begins approximately 8 days after full-thickness wounding and peaks at 12 to 14 days $[4,28,38]$. Our results demonstrated that FGF-2 levels in the sensory group were significantly greater than those in the motor and control groups on the third day postinjury $(p<0.05)$. In the motor group, FGF-2 levels were significantly decreased compared with those in the control group on

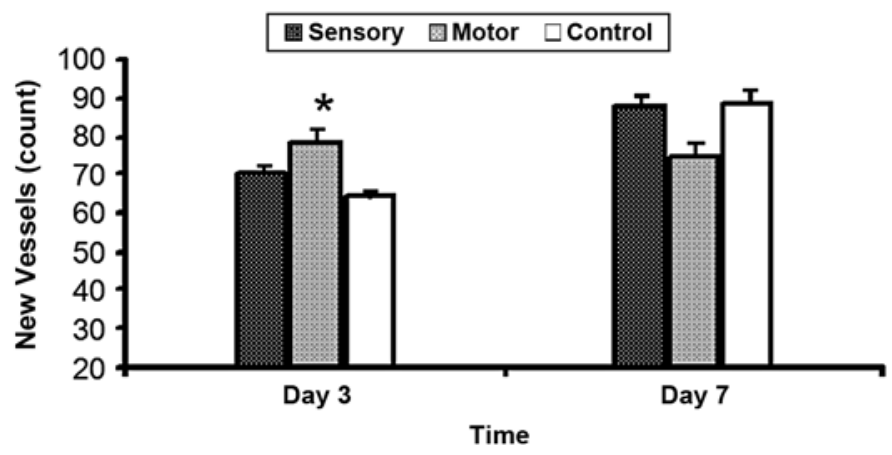

Figure 4.

Count of new blood vessels at wound site in experimental and control groups on days 3 and 7 postinjury. Values are expressed as mean \pm standard error of mean. ${ }^{*} p<0.05$ compared with control values. 
JRRD, Volume 50, Number 4, 2013

Table 2.

Mean \pm standard error of mean of percent of normalized biomechanical parameters on day 21 postinjury.

\begin{tabular}{lccc}
\hline Group & Stiffness & Tensile Strength & Strain \\
\hline Sensory & $73.4 \pm 12.2$ & $34.5 \pm 3.7$ & $52.0 \pm 7.6$ \\
Motor & $87.1 \pm 10.1$ & $39.4 \pm 4.6$ & $45.3 \pm 5.4$ \\
Control & $74.5 \pm 9.7$ & $35.6 \pm 4.9$ & $49.0 \pm 6.0$ \\
\hline \hline
\end{tabular}

day $3(p<0.05)$. The application of sensory ES to incisional wounds appears to effectively induce the expression of FGF-2 in the early phase of wound healing. In our previous study, we reported that sensory ES can induce greater release of VEGF on day 7 after incisional wounding [16]. It seems that FGF-2 plays some role in VEGF signaling and upregulation of VEGF expression [7,39]. Thus, according to results of the present study and those of our previous study, sensory ES, via an increase in expression of FGF-2 during the early phase of healing, may induce upregulation of VEGF during the proliferation phase of the healing process. The reason why sensory ES was more effective in the release of FGF-2 at the wound site is yet unclear, but may be related to the ability of microamperage ES to mimic the natural electrical field, or current, created following injury that facilitates the migration of cells toward the wound site [40-41]. The fibroblasts, endothelial cells, and macrophages, as predominant producers of FGF-2 at the wound site [7,2829], migrate toward the cathode $[9,34]$. Therefore, cathodal sensory ES induces greater release of FGF-2 at the wound site via stimulation of the migration of cells that produce FGF-2 toward the wound site.

In this study, a significant increase in FGF-2 levels was not observed in muscle under the wound site in any groups on either day 3 or 7 postinjury. This finding is in accordance with those of previous studies $[18,24]$. Shen et al. reported that different frequencies of ES did not increase FGF-2 expression in rabbit skeletal muscle [24]. Nagasaka et al. applied low-voltage ES to rat skeletal muscle with a stimulus intensity below the threshold for muscle contraction for a period of 5 days [18]. Their results demonstrated that bFGF expression was not increased in rat skeletal muscle. Of course, several studies have reported that ES of skeletal muscle led to an increase in FGF-2 expression [25,42]. In our previous study, we reported that sensory and motor ES did not induce the release of VEGF in rat skeletal muscle [16]. Thus, we surmise that ES, with the parameters used in our study, does not induce the release of angiogenic factors (FGF-2 and VEGF) in normal skeletal muscles.

Several studies have examined the effect of microamperage ES on histological parameters at the animal wound site [30-33,43-44]. Demir et al. [31], Weiss et al. [43], and Taskan et al. [44] reported that microamperage ES led to a decrease in PNLs and mast cell numbers at the wound site. Their findings indicated a decrease in the duration of the inflammatory phase in the ES group compared with the control group. In the present study, sensory ES decreased PNL numbers during the healing period compared with motor ES and control groups and also caused a significant decrease in mast cells compared with motor ES and control groups on day 3 and compared with the control group on day 7 postwounding. The number of PNLs and mast cells was increased in the motor group on day 3 postwounding compared with the control group. However, on day 7, the number of PNLs and mast cells was decreased in the motor and sensory groups compared with the control group. Thus, application of motor ES during the early phase of wound healing may increase the inflammation activity of the wound-healing process.

There are controversial results from previous studies regarding the effects of ES on the biomechanical properties of healed wounds [30-31,34,36-37,45-48]. Although a comparison of the biomechanical properties showed no statistically significant differences between the normalized ultimate strength, stiffness, and strain in the groups, these biomechanical properties tended to be higher in the motor ES group. It is suggested that motor ES may have beneficial effects on the proliferation and alignment of collagen fibers by improving the biomechanical environment of the wound site. On day 21, the treated wound in the sensory ES group showed complete regeneration of epithelium and organization of the underlying structures. Furthermore, collagen fibers were uniformly distributed in the dermis with a parallel arrangement related to the skin surface (Figure 5(a)), and newly formed vessels were scattered from the surface to deep within the skin. This distribution of new vessels may be related to the increase in the expression of FGF-2 and VEGF following the sensory ES on days 3 and 7 postinjury, respectively. In the motor ES group, the density of collagen fibers in the surface layer of the dermis was more obvious than that of the two other groups. Moreover, the collagen fibers in the motor ES group were aligned nearly parallel to the skin surface (Figure 5(b)). Newly formed vessels in the motor ES group were mainly distributed in the surface layer of 


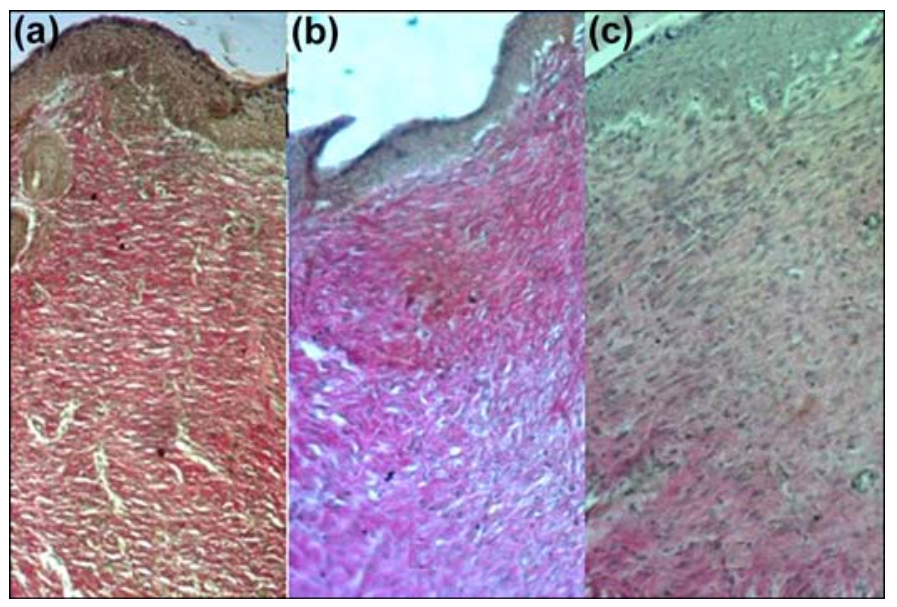

Figure 5.

Collagen fiber (red color) density in healed skin in (a) sensory electrical stimulation (ES) group, (b) motor ES group, and (c) control group. In sensory ES, collagen fibers were uniformly distributed in dermis with parallel arrangement related to skin surface, but in motor ES, concentration of collagen fibers was in surface layer of dermis and these fibers were arranged in parallel. Collagen fiber deposition was very low in control group.

the dermis, which is consistent with higher collagen density in the surface layer of the dermis and the nonsignificant increase in mechanical strength of the skin in this group. In the control group, little deposition of collagen fibers was seen on day 21 postinjury (Figure 5(c)). Sensory ES may be more effective in enhancing the expression of VEGF and FGF-2 in skin after wounding, but this effect does not significantly increase the number of new vessels. The increase of stimulus intensity above the motor threshold (the motor ES) enhanced the proliferation of collagen fibers, especially in the surface layer of the dermis; however, this enhancement had no significant effect on improvement of the biomechanical properties of the healed wound. No difference was found in muscle FGF-2 levels on days 3 and 7 after application of the sensory and motor ES. Future studies should be designed to clarify the effect of growth factor expression on the remodeling phase of long-term wound healing.

\section{CONCLUSIONS}

The application of sensory ES during the early stage of wound healing (inflammation phase and early proliferation phase) induces beneficial effects on wound healing by the release of angiogenic factors and decreases the duration of the inflammation phase. Application of motor ES during the late stage of healing (late proliferation and remodeling phase) produces better results on collagen density and the biomechanical properties of the healed wound. Therefore, different intensities of ES should likely be applied for the different stages of healing to obtain optimal effects.

\section{ACKNOWLEDGMENTS}

\section{Author Contributions:}

Study concept and design: G. Torkaman, M. R. Asadi.

Acquisition of data: M. R. Asadi, G. Torkaman, M. Hedayati, M. Mofid. Analysis and interpretation of data: G. Torkaman, M. Mofid, M. R. Asadi. Drafting of manuscript: G. Torkaman, M. R. Asadi, M. Hedayati. Critical revision of manuscript for important intellectual content: G. Torkaman, M. R. Asadi, M. Hedayati, M. Mofid.

Statistical analysis: M. R. Asadi, G. Torkaman.

Obtained funding: G. Torkaman.

Financial Disclosures: The authors have declared that no competing interests exist.

Funding/Support: This material was based on work supported by the Iran National Science Foundation (grant 87040798) and the facilities of Tarbiat Modares University, Tehran, Islamic Republic of Iran.

Institutional Review: This study was approved by the Ethics Commission of Tarbiat Modares University, Tehran, Islamic Republic of Iran.

\section{REFERENCES}

1. Beldon P. Basic science of wound healing. Surgery (Oxford). 2010;28(9):409-12. http://dx.doi.org/10.1016/j.mpsur.2010.05.007

2. Schreml S, Szeimies RM, Prantl L, Landthaler M, Babilas P. Wound healing in the 21 st century. J Am Acad Dermatol. 2010;63(5):866-81. [PMID:20576319] http://dx.doi.org/10.1016/j.jaad.2009.10.048

3. Eming SA, Brachvogel B, Odorisio T, Koch M. Regulation of angiogenesis: wound healing as a model. Prog Histochem Cytochem. 2007;42(3):115-70. [PMID:17980716] http://dx.doi.org/10.1016/j.proghi.2007.06.001

4. Bao P, Kodra A, Tomic-Canic M, Golinko MS, Ehrlich HP, Brem $\mathrm{H}$. The role of vascular endothelial growth factor in wound healing. J Surg Res. 2009;153(2):347-58.

[PMID:19027922]

http://dx.doi.org/10.1016/j.jss.2008.04.023

5. Lynch SE, Colvin RB, Antoniades HN. Growth factors in wound healing. Single and synergistic effects on partial thickness porcine skin wounds. J Clin Invest. 1989;84(2): 640-46. [PMID:2788174] http://dx.doi.org/10.1172/JCI114210 
6. Miyazono K, Usuki K, Heldin CH. Platelet-derived endothelial cell growth factor. Prog Growth Factor Res. 1991; 3(3):207-17. [PMID:1811791] http://dx.doi.org/10.1016/0955-2235(91)90007-Q

7. Presta M, Andrés G, Leali D, Dell'Era P, Ronca R. Inflammatory cells and chemokines sustain FGF2-induced angiogenesis. Eur Cytokine Netw. 2009;20(2):39-50. [PMID:19541589]

8. Presta M, Dell'Era P, Mitola S, Moroni E, Ronca R, Rusnati M. Fibroblast growth factor/fibroblast growth factor receptor system in angiogenesis. Cytokine Growth Factor Rev. 2005;16(2):159-78. [PMID:15863032] http://dx.doi.org/10.1016/j.cytogfr.2005.01.004

9. Kloth LC. Electrical stimulation for wound healing: a review of evidence from in vitro studies, animal experiments, and clinical trials. Int J Low Extrem Wounds. 2005; 4(1):23-44. [PMID:15860450] http://dx.doi.org/10.1177/1534734605275733

10. Ennis WJ, Lee C, Meneses P. A biochemical approach to wound healing through the use of modalities. Clin Dermatol. 2007;25(1):63-72. [PMID:17276203]

http://dx.doi.org/10.1016/j.clindermatol.2006.09.008

11. Zhao M, Penninger J, Isseroff RR. Electrical activation of wound-healing pathways. Adv Skin Wound Care. 2010;1: 567-73. [PMID:22025904]

12. Ramadan A, Elsaidy M, Zyada R. Effect of low-intensity direct current on the healing of chronic wounds: a literature review. J Wound Care. 2008;17(7):292-96. [PMID:18705230]

13. Taylor RR, Sladkevicius E, Guest JF. Modelling the costeffectiveness of electric stimulation therapy in non-healing venous leg ulcers. J Wound Care. 2011;20(10):464-72. [PMID:22067884]

14. Recio AC, Felter CE, Schneider AC, McDonald JW. Highvoltage electrical stimulation for the management of stage III and IV pressure ulcers among adults with spinal cord injury: demonstration of its utility for recalcitrant wounds below the level of injury. J Spinal Cord Med. 2012;35(1): 58-63. [PMID:22330192] http://dx.doi.org/10.1179/2045772311Y.0000000044

15. Balakatounis KC, Angoules AG. Low-intensity electrical stimulation in wound healing: review of the efficacy of externally applied currents resembling the current of injury. Eplasty. 2008;8:e28. [PMID:18552975]

16. Asadi MR, Torkaman G, Hedayati M. Effect of sensory and motor electrical stimulation in vascular endothelial growth factor expression of muscle and skin in full-thickness wound. J Rehabil Res Dev. 2011;48(3):195-201.

[PMID:21480094] http://dx.doi.org/10.1682/JRRD.2009.11.0182

17. Zhao M, Bai H, Wang E, Forrester JV, McCaig CD. Electrical stimulation directly induces pre-angiogenic responses in vascular endothelial cells by signaling through VEGF receptors. J Cell Sci. 2004;117(Pt 3):397-405.

[PMID:14679307]

http://dx.doi.org/10.1242/jcs.00868

18. Nagasaka M, Kohzuki M, Fujii T, Kanno S, Kawamura T, Onodera H, Itoyama Y, Ichie M, Sato Y. Effect of lowvoltage electrical stimulation on angiogenic growth factors in ischaemic rat skeletal muscle. Clin Exp Pharmacol Physiol. 2006;33(7):623-27. [PMID:16789930] http://dx.doi.org/10.1111/j.1440-1681.2006.04417.x

19. Hang J, Kong L, Gu JW, Adair TH. VEGF gene expression is upregulated in electrically stimulation rat skeletal muscle. Am J Physiol. 1995;269(5):HI827-31.

20. Kanno S, Oda N, Abe M, Saito S, Hori K, Handa Y, Tabayashi K, Sato Y. Establishment of a simple and practical procedure applicable to therapeutic angiogenesis. Circulation. 1999;99(20):2682-87. [PMID:10338463] http://dx.doi.org/10.1161/01.CIR.99.20.2682

21. Morris KA, McGee MF, Jasper JJ, Bogie KM. Evaluation of electrical stimulation for ischemic wound therapy: a feasibility study using the lapine wound model. Arch Dermatol Res. 2009;301(4):323-27. [PMID:19050907] http://dx.doi.org/10.1007/s00403-008-0918-2

22. Annex BH, Torgan CE, Lin P, Taylor DA, Thompson MA, Peters KG, Kraus WE. Induction and maintenance of increased VEGF protein by chronic motor nerve stimulation in skeletal muscle. Am J Physiol. 1998;274(3 Pt 2):H860-67. [PMID:9530197]

23. Amaral SL, Linderman JR, Morse MM, Greene AS. Angiogenesis induced by electrical stimulation is mediated by angiotensin II and VEGF. Microcirculation. 2001;8(1): 57-67. [PMID:11296854]

24. Shen M, Gao J, Li J, Su J. Effect of stimulation frequency on angiogenesis and gene expression in ischemic skeletal muscle of rabbit. Can J Physiol Pharmacol. 2009;87(5): 396-401. [PMID:19448738] http://dx.doi.org/10.1139/Y09-007

25. Düsterhöft S, Putman CT, Pette D. Changes in FGF and FGF receptor expression in low-frequency-stimulated rat muscles and rat satellite cell cultures. Differentiation. 1999;65(4):203-8. [PMID:10653356]

26. Fredericks DC, Smucker J, Petersen EB, Bobst JA, Gan JC, Simon BJ, Glazer P. Effects of direct current electrical stimulation on gene expression of osteopromotive factors in a posterolateral spinal fusion model. Spine (Phila $\mathrm{Pa}$ 1976). 2007;32(2):174-81.

27. Sato T, Lee TS, Takamatsu F, Fujikado T. Induction of fibroblast growth factor- 2 by electrical stimulation in cultured retinal Mueller cells. Neuroreport. 2008;19(16):1617-21. [PMID:18815585] http://dx.doi.org/10.1097/WNR.0b013e3283140f25 
28. Kibe Y, Takenaka H, Kishimoto S. Spatial and temporal expression of basic fibroblast growth factor protein during wound healing of rat skin. Br J Dermatol. 2000;143(4): 720-27. [PMID:11069447] http://dx.doi.org/10.1046/j.1365-2133.2000.03824.x

29. Powers CJ, McLeskey SW, Wellstein A. Fibroblast growth factors, their receptors and signaling. Endocr Relat Cancer. 2000;7(3):165-97. [PMID:11021964] http://dx.doi.org/10.1677/erc.0.0070165

30. Bayat M, Asgari-Moghadam Z, Maroufi M, Rezaie FS, Bayat M, Rakhshan M. Experimental wound healing using microamperage electrical stimulation in rabbits. J Rehabil Res Dev. 2006;43(2):219-26. [PMID:16847788] http://dx.doi.org/10.1682/JRRD.2005.05.0089

31. Demir H, Balay H, Kirnap M. A comparative study of the effects of electrical stimulation and laser treatment on experimental wound healing in rats. J Rehabil Res Dev. 2004;41(2):147-54. [PMID:15558369] http://dx.doi.org/10.1682/JRRD.2004.02.0147

32. Thawer HA, Houghton PE. Effects of electrical stimulation on the histological properties of wounds in diabetic mice. Wound Repair Regen. 2001;9(2):107-15.

[PMID:11350648]

http://dx.doi.org/10.1046/j.1524-475x.2001.00107.x

33. Leffmann DJ, Arnall DA, Holmgren PR, Cornwall MW. Effect of microamperage stimulation on the rate of wound healing in rats: a histological study. Phys Ther. 1994;74(3): 195-200, discussion 213-18. [PMID:8115453]

34. Talebi G, Torkaman G, Firoozabadi M, Shariat S. Effect of anodal and cathodal micro-amperage direct current on the skin wound healing: A biomechanical and histological study. J Biomech. 2007;40(S2):S662.

http://dx.doi.org/10.1016/S0021-9290(07)70650-4

35. Talebi G, Torkaman G, Firoozabadi M, Shariat S. Effect of anodal and cathodal microamperage direct current electrical stimulation on injury potential and wound size in guinea pigs. J Rehabil Res Dev. 2008;45(1):153-59.

[PMID:18566934]

http://dx.doi.org/10.1682/JRRD.2007.05.0068

36. Mehmandoust FG, Torkaman G, Firoozabadi M, Talebi G. Anodal and cathodal pulsed electrical stimulation on skin wound healing in guinea pigs. J Rehabil Res Dev. 2007; 44(4):611-18. [PMID:18247258]

http://dx.doi.org/10.1682/JRRD.2007.01.0007

37. Jamshidi F, Torkaman G, Firoozabadi M. The effect of cathodal and anodal electrical stimulation (IDC) on the biomechanical properties of pressure sore in guinea pig. J Biomech. 2006;39(Suppl 1):S394. http://dx.doi.org/10.1016/S0021-9290(06)84595-1

38. Shukla A, Dubey MP, Srivastava R, Srivastava BS. Differential expression of proteins during healing of cutaneous wounds in experimental normal and chronic models. Bio- chem Biophys Res Commun. 1998;244(2):434-39.

[PMID:9514941]

http://dx.doi.org/10.1006/bbrc.1998.8286

39. Fujihara Y, Koyama H, Ohba M, Tabata Y, Fujihara H, Yonehara Y, Takato T. Controlled delivery of bFGF to recipient bed enhances the vascularization and viability of an ischemic skin flap. Wound Repair Regen. 2008;16(1): 125-31. [PMID:18211584] http://dx.doi.org/10.1111/j.1524-475X.2007.00339.x

40. Kloth LC, McCulloch JM. Promotion of wound healing with electrical stimulation. Adv Wound Care. 1996;9(5): 42-45. [PMID:9069747]

41. Poltawski L, Watson T. Bioelectricity and microcurrent therapy for tissue healing - a narrative review. Phys Ther Rev. 2009;14(2):104-14. http://dx.doi.org/10.1179/174328809X405973

42. Morrow NG, Kraus WE, Moore JW, Williams RS, Swain JL. Increased expression of fibroblast growth factors in a rabbit skeletal muscle model of exercise conditioning. J Clin Invest. 1990;85(6):1816-20. [PMID:2347914] http://dx.doi.org/10.1172/JCI114640

43. Weiss DS, Eaglstein WH, Falanga V. Exogenous electric current can reduce the formation of hypertrophic scars. J Dermatol Surg Oncol. 1989;15(12):1272-75. [PMID:2592666]

44. Taşkan I, Özyazgan I, Tercan M, Kardaş HY, Balkanli S, Saraymen R, Zorlu U, Ozügül Y. A comparative study of the effect of ultrasound and electrostimulation on wound healing in rats. Plast Reconstr Surg. 1997;100(4):966-72. [PMID:9290665]

45. Naeini AT, Oryan A, Dehghani S, Nikahval B. Experimental cutaneous wound healing in rabbits: using continuous microamperage low-voltage electrical stimulation. Comp Clin Path. 2008;17(3):203-10. http://dx.doi.org/10.1007/s00580-008-0724-4

46. Wu KT, Go N, Dennis C, Enquist I, Sawyer PN. Effects of electric currents and interfacial potentials on wound healing. J Surg Res. 1967;7(3):122-28. [PMID:6020271] http://dx.doi.org/10.1016/0022-4804(67)90096-0

47. Brown M, McDonnell MK, Menton DN. Electrical stimulation effects on cutaneous wound healing in rabbits. A follow-up study. Phys Ther. 1988;68(6):955-60. [PMID:3259701]

48. Byl NN, McKenzie AL, West JM, Whitney JD, Hunt TK, Hopf HW, Scheuenstuhl H. Pulsed microamperage stimulation: a controlled study of healing of surgically induced wounds in Yucatan pigs. Phys Ther. 1994;74(3):201-13, discussion 213-18. [PMID:8115454]

Submitted for publication April 28, 2012. Accepted in revised form August 21, 2012. 
JRRD, Volume 50, Number 4, 2013

This article and any supplemental material should be cited as follows:

Asadi MR, Torkaman G, Hedayati M, Mofid M. Role of sensory and motor intensity of electrical stimulation on fibroblastic growth factor-2 expression, inflammation, vascularization, and mechanical strength of full-thickness wounds. J Rehabil Res Dev. 2013;50(4):489-98.

http://dx.doi.org/10.1682/JRRD.2012.04.0074

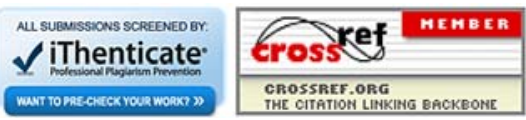

